\title{
Association of vegetarian diet with inflammatory biomarkers: a systematic review and meta-analysis of observational studies
}

\author{
Fahimeh Haghighatdoost ${ }^{1,2}$, Nick Bellissimo ${ }^{3}$, Julia O Totosy de Zepetnek ${ }^{3}$ and \\ Mohammad Hossein Rouhani ${ }^{1,2, *}$ \\ ${ }^{1}$ Food Security Research Center, Isfahan University of Medical Sciences, Hezar Jarib Street, PO Box 81745, Isfahan, \\ Islamic Republic of Iran: ${ }^{2}$ Department of Community Nutrition, School of Nutrition and Food Science, Isfahan University of \\ Medical Sciences, Isfahan, Islamic Republic of Iran: ${ }^{3}$ School of Nutrition, Ryerson University, Toronto, Ontario, Canada
}

Submitted 11 August 2016: Final revision received 25 April 2017: Accepted 16 June 2017: First published online 24 August 2017

\begin{abstract}
Objective: Vegetarian diets contain various anti-inflammatory components. We aimed to investigate the effects of vegetarianism on inflammatory biomarkers when compared with omnivores.

Design: Systematic review and meta-analysis.

Setting: Literature search was conducted in Science Direct, Proquest, MEDLINE and Google Scholar up to June 2016. Summary estimates and corresponding $95 \%$ CI were derived via the DerSimonian and Laird method using random effects, subgroup analyses were run to find the source of heterogeneity and a fixed-effect model examined between-subgroup heterogeneity.

Subjects: Studies were included if they evaluated effects of any type of vegetarianism compared with omnivores on circulating levels of inflammatory biomarkers. No restriction was made in terms of language or the date of study publications.

Results: Eighteen articles were included. Pooled effect size showed no difference in high-sensitivity C-reactive protein (hs-CRP) levels in vegetarians $v$. omnivores (Hedges' $g=-0.15 ; 95 \%$ CI $-0.35,0 \cdot 05)$, with high heterogeneity $\left(I^{2}=75.6 \%\right.$, $P<0 \cdot 01)$. A subgroup analysis by minimum duration of vegetarianism showed that a minimum duration of 2 years vegetarianism was associated with lower hs-CRP levels $v$. omnivores (Hedges' $g=-0.29$; $95 \%$ CI -0.59 , 0.01), with moderate heterogeneity $\left(I^{2}=68.9 \%, P<0.01\right)$. No significant effect was found in studies using a minimum duration of 6 months of vegetarianism, with low heterogeneity. Vegetarianism was associated with increased IL-6 concentrations $(0 \cdot 21 \mathrm{pg} / \mathrm{ml} ; 95 \%$ CI $0 \cdot 18,0 \cdot 25)$, with no heterogeneity $\left(I^{2}=0 \cdot 0 \%, P=0 \cdot 60\right)$.

Conclusions: The meta-analysis provides evidence that vegetarianism is associated with lower serum concentrations of hs-CRP when individuals follow a vegetarian diet for at least 2 years. Further research is necessary to draw appropriate conclusions regarding potential associations between vegetarianism and IL-6 levels. A vegetarian diet might be a useful approach to manage inflammaging in the long term.
\end{abstract}

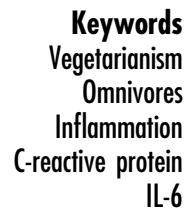

Low-grade chronic inflammation (inflammaging) is a known risk factor for the development of age-related diseases such as CVD, diabetes and some cancers. Inflammaging can occur as a result of cell damage and/or from environmental factors such as dietary intakes, gut microbiota and obesity ${ }^{(1)}$. Elevated levels of high-sensitivity C-reactive protein (hs-CRP), TNF- $\alpha$ and IL- 6 contribute to the pathogenesis of these age-related diseases ${ }^{(1)}$ and can be used to predict 10-year all-cause mortality in older adults $^{(2)}$.
Vegetarian diets have been shown to effectively reduce the risk of obesity, hypertension ${ }^{(3)}$, type 2 diabetes and insulin resistance $^{(3-5)}$, dyslipidaemia (particularly elevated cholesterol levels) ${ }^{(6)}$, CVD $^{(7)}$ and mortality (from either CVD or cancer) ${ }^{(8)}$. While the definition of vegetarianism varies, when compared with omnivores diets, vegetarian diets typically have larger amounts of antioxidant micronutrients such as vitamins $\mathrm{C}$ and E, phytochemicals and fibre ${ }^{(9)}$. These healthful components may ameliorate inflammatory processes and decrease circulating levels of inflammatory biomarkers, thereby reducing the 
risk of age-related diseases. Numerous studies have reported lower serum concentrations of inflammatory biomarkers among vegetarians compared with omnivores ${ }^{(10-14)}$, and vegan and vegetarian diets have been shown to substantially alter faecal flora ${ }^{(15)}$ that play an important role in the inflammatory response ${ }^{(16)}$. A recent lifestyle intervention study indicated that vegans and vegetarians have lower levels of systematic inflammation compared with omnivores ${ }^{(17)}$.

Most of the available evidence regarding vegetarianism and chronic inflammation comes from observational studies, and their results are inconsistent. The majority of studies suggest lower levels of inflammation in vegetarians $v$. omnivores $^{(9-13)}$, while other investigations have not found significant differences between groups $^{(18,19)}$ or have reported greater levels of inflammatory markers (e.g. IL-6 and hs-CRP) in vegetarians ${ }^{(20)}$. Two meta-analyses from 2012 and 2015 suggested a lower risk of mortality from IHD and cancer $^{(8)}$, and lower serum levels of total cholesterol, LDL cholesterol and HDL cholesterol ${ }^{(6)}$, in vegetarians compared with non-vegetarians, respectively; however, no systematic review or meta-analysis has evaluated the role of vegetarianism on serum levels of inflammatory biomarkers. Since chronic inflammation plays an important role in the pathogenesis of chronic diseases and premature mortality, it is possible that the beneficial effects from a vegetarian diet are mediated by lower inflammation. The present metaanalysis was conducted using published data from observational studies to assess the effects of a vegetarian diet on serum levels of selected inflammatory biomarkers.

\section{Materials and methods}

The meta-analysis was planned, conducted and reported according to the recommendations of the Preferred Reporting Items for Systematic Reviews and Meta-Analyses (PRISMA) statement ${ }^{(21)}$.

\section{Search strategy}

A systematic search was conducted to identify relevant articles using Science Direct (www.sciencedirect.com/science/ journals), Proquest (www.proquest.com), MEDLINE (www. pubmed.com) and Google Scholar (scholar.google.com) databases up to June 2016. No restriction was made in terms of language or the date of study publications. The following search terms were used in literature search: 'vegetarian' OR 'vegan' OR 'plant based diet' OR 'vegetarianism' in combination with 'acute-phase proteins' OR 'Inflammation' OR 'C-reactive protein' OR 'interleukins' OR 'tumor necrosis factor-alpha' OR 'inflammatory'. The reference lists of related original and review articles were checked for additional relevant articles using a manual approach.

\section{Eligibility criteria}

Studies were eligible for inclusion in the meta-analysis if they reported effects of any type of vegetarianism (vegan, vegetarian, lactovegetarian, ovovegetarian and lacto-ovovegetarian), in comparison with an omnivorous diet, on circulating levels of inflammatory biomarkers in adults. No specific criterion was considered for the duration of being on a vegetarian diet. Studies were excluded if they assessed the effects of a general healthy lifestyle that included a vegetarian diet as one component. Two independent assessors (F.H. and M.H.R.) read titles and abstracts of the retrieved articles for inclusion and exclusion criteria; disagreements were resolved by consensus (Table 1).

\section{Data extraction and quality assessment}

The following information was extracted from each article: first author's last name, publication year, sample size, sex and age of subjects, study design, duration of being on a vegetarian diet, type of vegetarianism and inflammatory biomarker values (mean with SD or SE) for both vegetarians and omnivores. Two assessors (F.H. and M.H.R.) evaluated study quality independently using the NewcastleOttawa scale for non-randomized studies ${ }^{(22)}$ and any discrepancy was resolved by discussion to reach consensus.

\section{Statistical analyses}

Effect size was calculated via Hedges' $g^{(23)}$ using the differences between means of serum levels of inflammatory markers (vegetarians $v$. omnivores) divided by their corresponding $\mathrm{SD}$.

The difference in means and SD for all inflammatory markers were extracted from each eligible study and used in the meta-analysis (vegetarians $v$. omnivores). Summary estimates and corresponding $95 \%$ CI were derived via the DerSimonian and Laird method using a random-effects model incorporating the between-study variation ${ }^{(24)}$. The $I^{2}$ statistic was used to evaluate the heterogeneity among the studies ${ }^{(25)}$, and $H^{2}$ was calculated as another measurement for assessing heterogeneity by dividing $Q$ by degrees of freedom ${ }^{(26)}$. Subgroup analyses were run to find the source of heterogeneity, and fixed-effect models used to examine between-subgroup heterogeneity. Sensitivity analysis was used to explore the extent to which summary estimates might be related to one particular study or a group of studies, done in accordance with the Cochrane handbook for systematic reviews of observational studies ${ }^{(27)}$. Publication bias was evaluated by Egger's regression asymmetry test and Begg's adjusted rank correlation test only for hs-CRP, but not for IL-6 due to limited number of studies. Statistical analyses were done using the statistical software package Stata version 11.2 and $P$ values of $<0.05$ were considered statistically significant.

\section{Results}

\section{Systematic review}

Our search retrieved 855 articles, eighteen of which were selected following screening the titles and abstracts $^{(9-13,18-20,28-37)}$ (Fig. 1). Characteristics of studies 


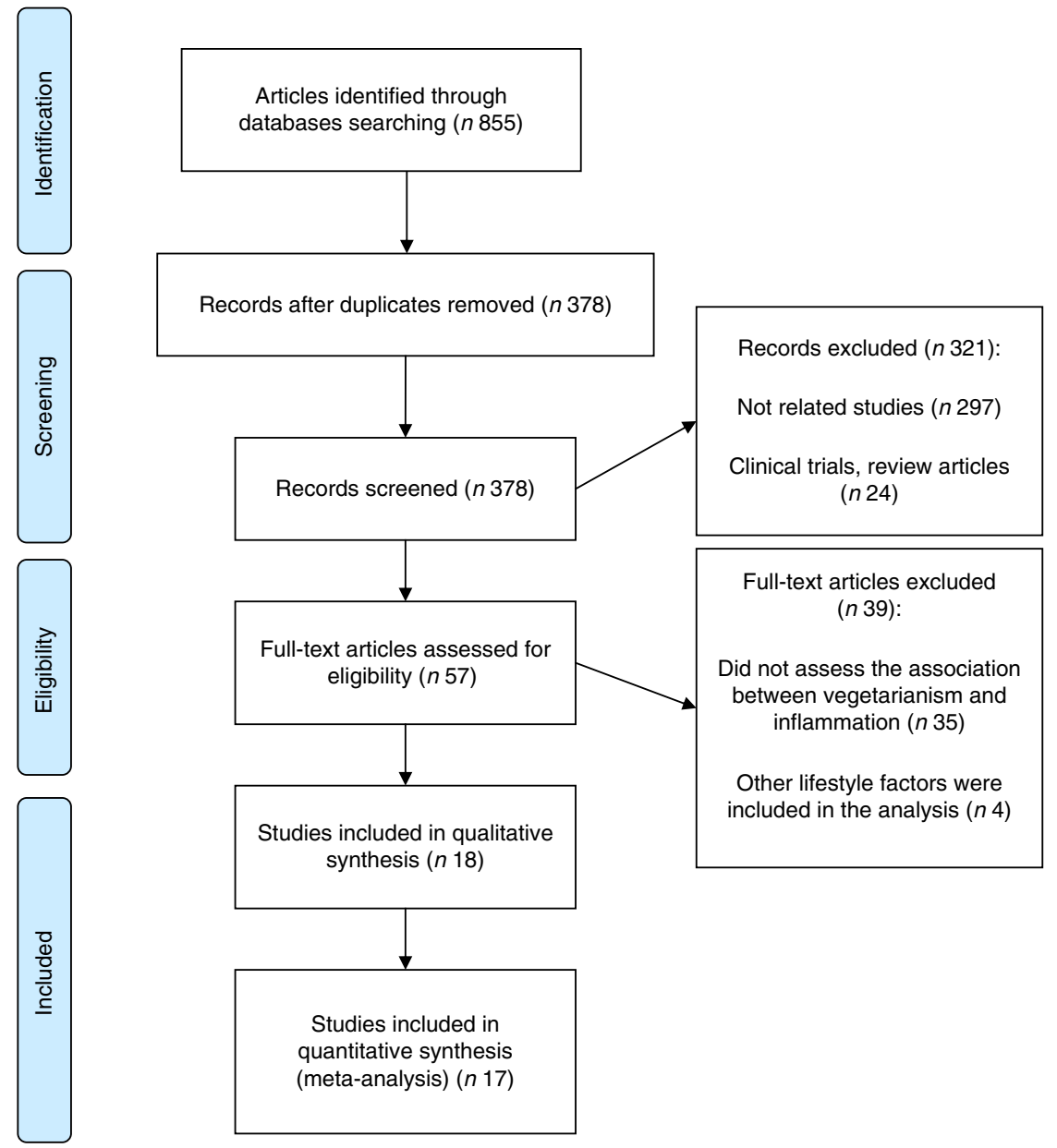

Fig. 1 Flowchart of the process of study selection

included in the systematic review are displayed in Table 1. The design of all studies was cross-sectional. Subjects were in the age range of 31 to 68 years, and duration of vegetarian diet ranged from $>6$ months to $>5$ years. Ten studies used matched groups or multivariate-adjusted models to report associations between vegetarianism and inflammatory marker(s) compared with omnivores $^{(12,13,18,19,29-33,35)}$. Seven studies implemented a $>2$-year duration of vegetarianism ${ }^{(10-13,29,32,33)}$. Eight studies reported lower concentrations of inflammatory marker(s) in vegetarians $v$. omnivores ${ }^{(9-13,28,29,31)}$, seven studies found no difference between groups $^{(19,30,32-36)}$, and three studies reported higher concentrations of inflammatory marker(s) in vegetarians $v$. omnivores ${ }^{(18,20,37)}$.

\section{Meta-analysis}

A meta-analysis was performed on seventeen studies including a total of 2398 subjects $^{(9-13,18-20,28-30,32-37)}$; the study by Paalani et $a l .{ }^{(31)}$ was not included in the metaanalysis because data were reported as median and interquartile range. Pooled effect size showed that there was no difference in hs-CRP levels in vegetarians $v$. omnivores (Hedges' $g=-0 \cdot 15 ; 95 \%$ CI -0.35 , 0.05;
$P=0 \cdot 20 ;$ Fig. 2). However, since heterogeneity was high ( $I^{2}=75.6 \%$ and $H^{2}=3.65, P<0.01$ for both), subgroup analysis was run using minimum duration of vegetarianism (Fig. 3). Overall effect size of studies employing a minimum duration of $\geq 2$ years of vegetarianism showed a trend towards lower hs-CRP level in vegetarians $v$. omnivores (Hedges' $g=-0 \cdot 29 ; 95 \% \mathrm{CI}-0.59,0 \cdot 01 ; P=0 \cdot 06$ ). No significant difference in hs-CRP levels between groups was found for studies employing a minimum duration of $\geq 6$ months of vegetarianism (Hedges' $g=-0.00 ; 95 \% \mathrm{CI}$ $-0.17,0.17 ; P=0.98)$. Heterogeneity was high in the $\geq 2$ years of vegetarianism subgroup $\left(I^{2}=68.9 \%\right.$ and $H^{2}=3.22, P<0.01$ for both) and low in the $\geq 6$ months of vegetarianism subgroup $\left(I^{2}=48.4 \%\right.$ and $H^{2}=1.94$, $P=0.06$ for both). Between-subgroup heterogeneity was significant $(P<0 \cdot 01)$. Subgroup analyses based on the type of vegetarian diet (vegan, vegetarian, lactovegetarian, ovovegetarian and lacto-ovovegetarian) provided no evidence indicating that it might be the source of heterogeneity ( $P$ between subgroups $=0.363$; see online supplementary material, Supplemental Fig. 1).

Comparison of IL-6 levels in vegetarians $v$. omnivores is shown in Fig. 4. Results suggest that vegetarians had 
Table 1 Characteristics of reviewed studies on the association of vegetarian diet with inflammatory biomarkers

\begin{tabular}{|c|c|c|c|c|c|c|c|c|c|}
\hline \multirow[b]{2}{*}{$\begin{array}{l}\text { First author's last name (year/ } \\
\text { country) and reference }\end{array}$} & \multirow[b]{2}{*}{$\begin{array}{c}\text { No. of } \\
\text { subjects (sex) }\end{array}$} & \multirow[b]{2}{*}{$\begin{array}{l}\text { Mean age } \\
\text { (years) }\end{array}$} & \multirow[b]{2}{*}{ Design } & \multicolumn{2}{|c|}{ Diets } & \multirow[b]{2}{*}{$\begin{array}{c}\text { Duration of } \\
\text { vegetarian diet }\end{array}$} & \multirow[b]{2}{*}{ Adjusted variables } & \multirow[b]{2}{*}{ Result } & \multirow[b]{2}{*}{$\begin{array}{l}\text { Study } \\
\text { quality score }\end{array}$} \\
\hline & & & & Vegetarian & Omnivores & & & & \\
\hline Montalcini $(2015 / \text { ltaly })^{(30)}$ & $52(\mathrm{M})$ & 30 & Cross-sectional & NR & NR & $>3$ years & $\mathrm{BMI}$ and age & $\begin{array}{l}\text { No significant difference in most } \\
\text { cytokines between } \\
\text { vegetarians and omnivores }\end{array}$ & 8 \\
\hline Yu (2014/China) $)^{(37)}$ & 195 (M) & 35 & Cross-sectional & Lacto-ovo & $\begin{array}{l}\text { Meat intake } \geq 5 \\
\text { times/week }\end{array}$ & $>6$ months & Unadjusted & Vegetarians had higher IL- 6 level & 6 \\
\hline Yang $(2011 / \text { China })^{(35)}$ & 229 (M) & 33 & Cross-sectional & Lacto-ovo & NR & $>1$ year & Age & $\begin{array}{l}\text { No significant difference in CRP } \\
\text { between vegetarians and } \\
\text { omnivores }\end{array}$ & 8 \\
\hline Su (2011/Taiwan) $)^{(33)}$ & $90(\mathrm{~F})$ & 58 & Cross-sectional & Lacto-ovo & NR & $>5$ years & Age & $\begin{array}{l}\text { No significant difference in CRP } \\
\text { between vegetarians and } \\
\text { omnivores }\end{array}$ & 7 \\
\hline Paalani $\left(2011 /\right.$ USA) ${ }^{(31)}$ & $216(\mathrm{NR})$ & 69 & Cross-sectional & Lacto-ovo & NR & $>1$ year & Multivariate & $\begin{array}{l}\text { Lower CRP (not IL-6) in } \\
\text { vegetarians }\end{array}$ & 7 \\
\hline $\begin{array}{l}\text { Krajcovicova-Kudlackova } \\
\left(2011 / \text { Slovakia) }{ }^{(29)}\right.\end{array}$ & $83(F)$ & 65 & Cross-sectional & Lacto-ovo & NR & Long-term & Age & Lower CRP in vegetarians & 7 \\
\hline Chen (2011/Taiwan) ${ }^{(28)}$ & 363 (NR) & 52 & Cross-sectional & Lacto-ovo & NR & $>1$ year & Unadjusted & Lower CRP in vegetarians & 7 \\
\hline Yen (2010/Taiwan) ${ }^{(36)}$ & 49 (both) & 35 & Cross-sectional & All types & NR & $>6$ months & Unadjusted & $\begin{array}{l}\text { No significant difference in CRP } \\
\text { between vegetarians and } \\
\text { omnivores }\end{array}$ & 7 \\
\hline Tiahou (2009/lvory Coast) ${ }^{(34)}$ & 112 (both) & 30 & Cross-sectional & NR & Fish consumers & $>1$ year & Unadjusted & $\begin{array}{l}\text { No significant difference in CRP } \\
\text { between vegetarians and } \\
\text { omnivores }\end{array}$ & 6 \\
\hline Chen $(2008 / \text { Taiwan })^{(10)}$ & 198 (both) & 50 & Cross-sectional & Lacto-ovo & NR & $>1$ year & Unadjusted & Lower CRP in vegetarians & 6 \\
\hline Sebeková (2001/Germany) ${ }^{(32)}$ & 61 (both) & 32 & Cross-sectional & All types & $\begin{array}{l}\text { Western mixed } \\
\text { diet }\end{array}$ & $>5$ years & Age & $\begin{array}{l}\text { No significant difference in CRP } \\
\text { between vegetarians and } \\
\text { omnivores }\end{array}$ & 8 \\
\hline Szeto $(2004 / \text { China })^{(14)}$ & 60 (both) & 44 & Cross-sectional & Lacto-ovo & NR & $>5$ years & Age and sex & Vegetarians had lower CRP level & 7 \\
\hline Fontana $(2005 / \text { USA })^{(13)}$ & 36 (both) & 55 & Cross-sectional & $\begin{array}{l}\text { Exclusively } \\
\text { plant food }\end{array}$ & $\begin{array}{l}\text { Typical American } \\
\text { diet }\end{array}$ & $>18$ months & $\begin{array}{l}\text { Age, sex and socio- } \\
\text { economic status }\end{array}$ & Vegetarians had lower CRP level & 8 \\
\hline Sebekova (2006/Slovakia) $)^{(18)}$ & 136 (both) & 30 & Cross-sectional & Lacto-ovo & $\mathrm{NR}$ & NR & $\begin{array}{l}\text { Physical activity and } \\
\text { education }\end{array}$ & Vegetarians had higher CRP level & 8 \\
\hline $\begin{array}{l}\text { Krajcovicova-Kudlackova } \\
(2005 / \text { Slovakia) }\end{array}$ & 270 (both) & 46 & Cross-sectional & Lacto-ovo & $\begin{array}{c}\text { Traditional mixed } \\
\text { diet }\end{array}$ & $>1$ year & Unadjusted & Vegetarians had lower CRP level & 6 \\
\hline Fontana $(2007 / \text { Italy })^{(11)}$ & 42 (both) & 53 & Cross-sectional & $\begin{array}{l}\text { Low-energy } \\
\text { low-protein } \\
\text { vegetarian } \\
\text { diet }\end{array}$ & NR & $>3$ years & Unadjusted & Vegetarians had lower CRP level & 7 \\
\hline Mezzano (1999/Chile) $)^{(19)}$ & 52 (both) & 31 & Cross-sectional & Lacto-ovo & NR & $>1$ year & $\begin{array}{l}\text { Age, sex and socio- } \\
\text { economic status }\end{array}$ & $\begin{array}{l}\text { No significant difference in CRP } \\
\text { between vegetarians and } \\
\text { omnivores }\end{array}$ & 7 \\
\hline Lee (2016/Taiwan) ${ }^{(20)}$ & 154 (both) & 61 & Cross-sectional & Lacto-ovo & NR & $>1$ year & Unadjusted & $\begin{array}{l}\text { Vegetarians had higher CRP and } \\
\text { IL-6 levels }\end{array}$ & 7 \\
\hline
\end{tabular}

M, male; F, female; NR, not reported; CRP, C-reactive protein. 


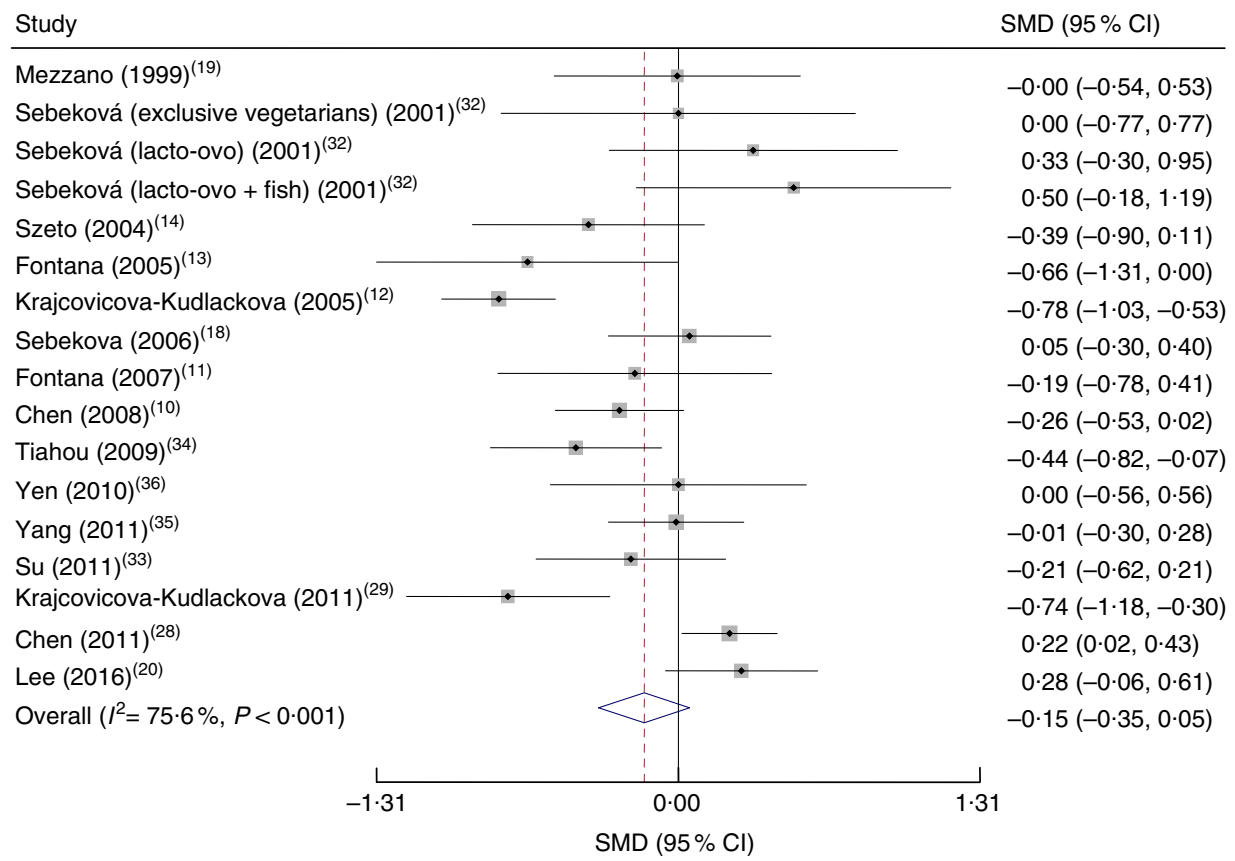

Fig. 2 Forest plot showing the overall effect of vegetarianism on C-reactive protein levels compared with omnivores. Results are effect size, presented as summarized mean difference (SMD), and $95 \% \mathrm{Cl}$. The study-specific SMD and $95 \% \mathrm{Cl}$ are represented by the black diamond and horizontal line, respectively; the area of the grey square is proportional to the specific-study weight to the overall meta-analysis. The centre of the open diamond and the vertical dashed line represent the overall effect size of all studies; the width of the diamond represents the overall pooled $95 \% \mathrm{Cl}$

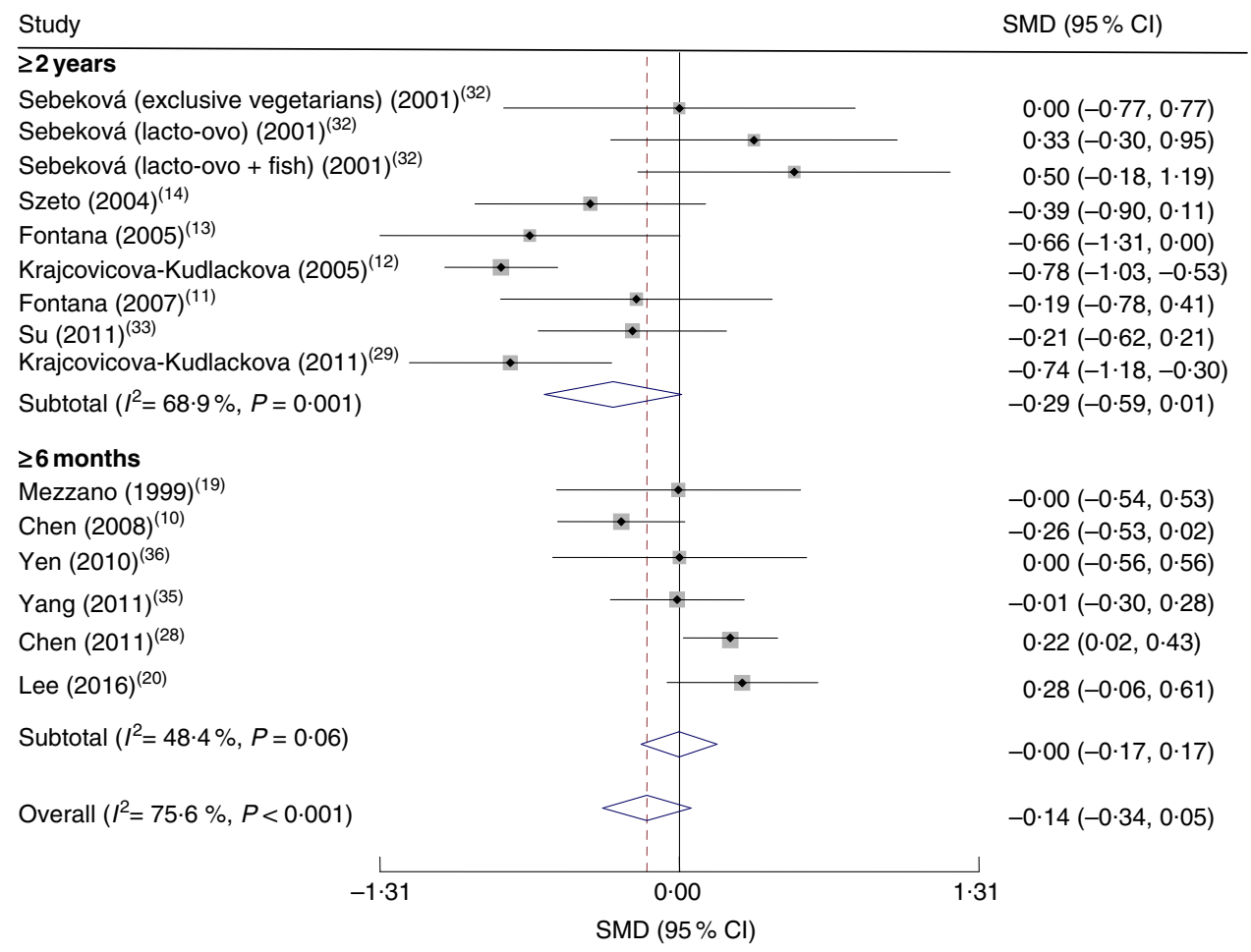

Fig. 3 Forest plot showing the overall effect of vegetarianism on C-reactive protein levels compared with omnivores by minimum duration of vegetarianism. Results are effect size, presented as summarized mean difference (SMD), and $95 \%$ Cl. The study-specific SMD and $95 \% \mathrm{Cl}$ are represented by the black diamond and horizontal line, respectively; the area of the grey square is proportional to the specific-study weight to the overall meta-analysis. The centre of the open diamond and the vertical dashed line represent the overall effect size of all studies; the width of the diamond represents the overall pooled $95 \% \mathrm{Cl}$ 


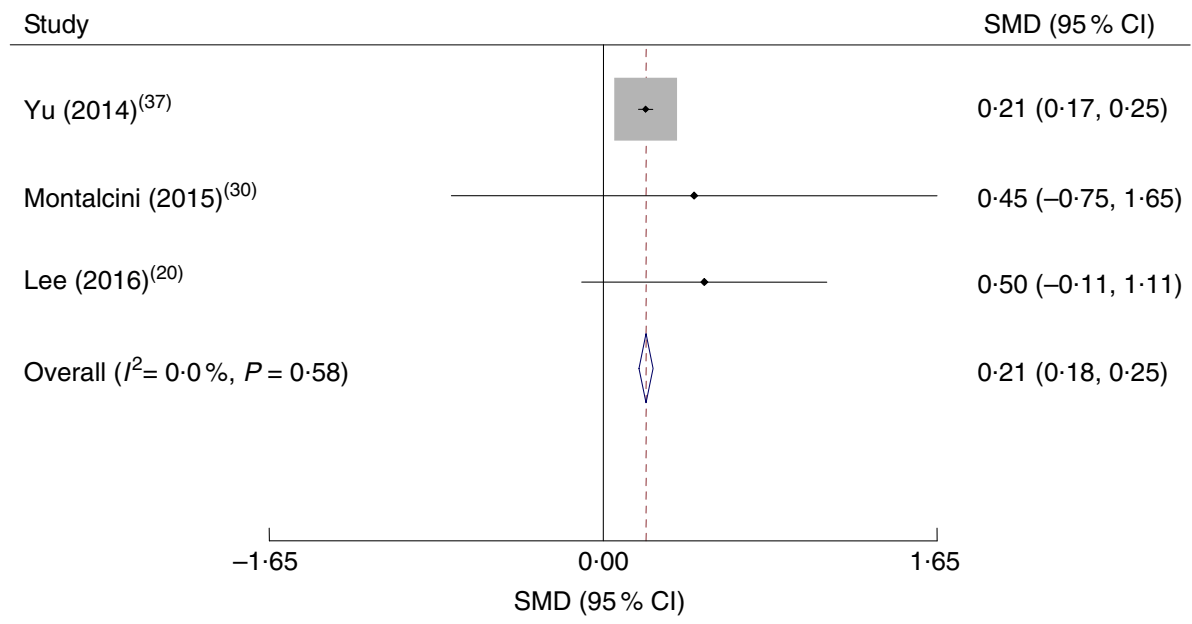

Fig. 4 Forest plot showing the overall effect of vegetarianism on IL-6 levels compared with omnivores. Results are effect size, presented as summarized mean difference (SMD), and $95 \% \mathrm{Cl}$. The study-specific SMD and $95 \% \mathrm{Cl}$ are represented by the black diamond and horizontal line, respectively; the area of the grey square is proportional to the specific-study weight to the overall metaanalysis. The centre of the open diamond and the vertical dashed line represent the overall effect size of all studies; the width of the diamond represents the overall pooled $95 \% \mathrm{Cl}$

higher IL-6 levels $v$. omnivores $(0 \cdot 21 \mathrm{pg} / \mathrm{ml}, 95 \%$ CI $0 \cdot 18$, $0.25 ; P<0.01)$, with no heterogeneity $\left(I^{2}=0.0 \%\right.$ and $\left.H^{2}=0.52, P=0.60\right)$.

\section{Sensitivity analysis and publication bias}

Sensitivity analysis was performed to determine the influence of each study on pooled effect size. The overall effect size of hs-CRP levels did not substantially change when individual studies were removed. In contrast, the pooled effect of IL-6 levels became insignificant after omission of the study by Yu et al. ${ }^{(37)}$. Begg's test and Egger's test did not find evidence of publication bias in hs-CRP (Begg's: $P=0 \cdot 60$; Egger's: $P=0.26$; see online supplementary material, Supplemental Fig. 2).

\section{Study quality}

Studies were categorized into high-quality or low-quality studies using a cut-off point of 7 . Accordingly, four studies scored 6 stars and had low quality ${ }^{(9,11,34,37)}$, nine studies scored 7 stars, and five studies scored 8 stars which categorized them as having high quality (Table 1).

\section{Discussion}

Vegetarians consume large amounts of grains, fruits, vegetables, legumes and nuts. Although the health outcomes of these food components have been widely assessed, there is no consensus regarding their anti-inflammatory effects. The present study found a trend towards lower hs-CRP concentrations in subjects who were on a vegetarian diet for at least 2 years, and higher IL- 6 concentrations were observed in vegetarians $v$. omnivores.

Although one study reported an association between mixed grains and hs-CRP levels ${ }^{(38)}$, the majority of studies assessed the effects of whole grains on hs-CRP. Two studies reported whole grains consumption had beneficial effects $^{(39,40)}$, while two others found no favourable effects of whole grains $v$. refined grains on inflammation ${ }^{(41,42)}$. Similar discrepancies were observed for associations of fruits and vegetables with inflammation: some studies reported inverse relationships ${ }^{(43,44)}$ while others found no association between vegetable consumption and hs-CRP levels ${ }^{(45,46)}$. Several studies reported indirect associations between fruit intake and inflammatory markers ${ }^{(38,45,46)}$; however, one study reported that hs-CRP levels depend on the type of fruit consumed ${ }^{(38)}$. Further, it seems that sex and BMI may influence the association between fruit and vegetable intake and hs-CRP levels ${ }^{(47)}$.

Several studies reported that nuts have a favourable effect on inflammation ${ }^{(48,49)}$, related to the large amounts of $\mathrm{Mg}$, fibre, $\alpha$-linolenic acid, L-arginine, antioxidants and MUFA $^{(50)}$. Other studies reported that nuts had no beneficial effect on inflammatory markers ${ }^{(51-53)}$. As the composition of various nuts differs ${ }^{(54)}$, the type of nuts consumed may play an important role in the observed anti-inflammatory effects of nut intake.

Similar to other components of vegetarian diets, findings regarding the effects of legumes on inflammatory markers are not consistent. Some studies reported no association between legumes and hs-CRP levels ${ }^{(45,55)}$, while Saraf-Bank et al. showed that high legume intake may reduce hs-CRP concentrations after 6 weeks ${ }^{(56)}$.

There are several agents in vegetarian diets (e.g. phytosterols, spices, salicylic acid and dietary fibre) that may mediate the anti-inflammatory effect of vegetarianism. Phytosterols are strong anti-inflammatory agents that reduce inflammatory makers ${ }^{(57-59)}$. Some spices typical in vegetarian diets have an anti-inflammatory effect through their inhibition of pro-inflammatory marker production ${ }^{(60,61)}$. 
Fruits and vegetables are known as dietary sources of salicylic acid ${ }^{(62,63)}$, an active ingredient of anti-inflammatory medications $^{(64)}$. Further, fruits and vegetables may modulate gut microbiota via dietary fibre. The ratio of the antiinflammatory bacterium, Faecalibacterium prausnitzii, is higher in vegetarian diets ${ }^{(15)}$. In addition, it has been suggested that vegetarian diets improve rheumatoid arthritis, an inflammatory disease, via changes in faecal flora ${ }^{(65)}$.

Subgroup analyses revealed that duration of vegetarianism was a source of heterogeneity. Lower hs-CRP concentrations were observed in subjects who had been on a vegetarian diet for at least 2 years, while studies including 'new' vegetarians (minimum duration of vegetarianism was 6 months) did not report any significant difference in hs-CRP levels when compared with omnivores. It seems there is a time interval between starting a vegetarian diet and reduction in hs-CRP level. Since beneficial effects of fruit and vegetable intake are in part mediated by changes in gut microbiota, perhaps longer durations are needed to observe beneficial health outcomes ${ }^{(66)}$.

The results of a sensitivity analysis revealed that pooled effects of IL-6 levels became non-significant after omission of the study by $\mathrm{Yu}$ et $a l{ }^{(37)}$. A closer look at the study design of these three reports revealed that $\mathrm{Yu}$ et $a l^{(37)}$ included subjects who had been vegetarians for a minimum of 6 months, while the other two studies ${ }^{(20,30)}$ assessed IL-6 levels in subjects who were on a vegetarian diet for at least 2 years. It appears that duration of vegetarianism should be considered when interpreting its effects on inflammation. Evaluating publication bias is relevant when the number of studies is larger than ten; since only three studies investigated IL-6 levels, publication bias was not evaluated and the results of this metaanalysis should be interpreted with caution.

The type of vegetarian diet in most studies included in the current systematic review and meta-analysis was lacto-ovo. Dairy products in vegetarian diet can be a double-edged sword. Although dairy products are sources of SFA, a pro-inflammatory fatty acid $^{(67)}$, they are important to meet Ca requirements ${ }^{(68)}$. To minimize unfavourable effects of dairy products in vegetarians, dairy products can be replaced by a rich source of dietary $\mathrm{Ca}$.

Several limitations should be addressed. First, although we observed elevated IL-6 levels in vegetarians $v$. omnivores, the number of studies included in the meta-analysis ( $n$ 3) was not sufficient to draw reliable conclusions. Further studies should be conducted to determine the association between vegetarianism and IL-6 levels. Second, our findings were drawn from cross-sectional data; longitudinal and intervention study designs may provide additional insight into the effects of vegetarianism on inflammaging. Third, dietary intakes among omnivores were not assessed. It is possible that omnivores adhered to healthy diets rich in fruits and vegetables (e.g. the DASH (Dietary Approaches to Stop Hypertension) diet). Although all studies included in the present meta-analysis used meat consumers as omnivores, they did not focus on the type of meat consumed. There is evidence that fish intake reduces serum levels of inflammatory markers ${ }^{(69,70)}$, whereas red meat increases inflammation ${ }^{(71,72)}$. Fourth, the definition of vegetarianism was not same across studies. Inconsistencies in the definition of a vegetarian diet in the literature limit generalizability of results. Fifth, the studies included did not assess food preparation methods; food preparation methods have an important role in the context of beneficial health effects of vegetables. For example, there is an inverse association between frying temperature and antiinflammation phytochemical contents of carrots (e.g. $\alpha$-carotene, $\beta$-carotene and total carotenoids) ${ }^{(73)}$. Most studies included in the present systematic review and meta-analyses were conducted in China or Taiwan. Previous studies have reported that frying foods, especially vegetables, in oil is a common cooking method in China and Taiwan ${ }^{(74)}$. Vegetarians residing in the USA consumed more healthy foods than vegetarians residing in South Asia ${ }^{(75)}$.

Although there are several limitations, the strengths of the current meta-analysis should be considered. To the best of our knowledge, it is the first meta-analysis that systematically reviewed and summarized associations of vegetarian diets with inflammatory biomarkers. Moreover, both Begg's rank correlation test and Egger's linear regression test demonstrated no evidence for publication bias.

\section{Conclusion}

In conclusion, results from the present study showed that those who followed a vegetarian diet for at least 2 years had lower serum concentrations of hs-CRP and increased concentrations of IL-6 in comparison with omnivores. However, only three studies assessed associations between vegetarians and IL-6; thus, findings regarding IL- 6 should be interpreted with caution and further evidence should be provided to draw a valid conclusion. In contrast, fifteen studies focused on hs-CRP levels; it can be concluded that vegetarianism has a favourable effect on hs-CRP levels. Future studies should compare different types of vegetarian diets.

\section{Acknowledgements}

Financial support: The study was supported by Food Security Research Center, Isfahan University of Medical Sciences, Isfahan, Iran. This paper was supported by the School of Nutrition and Food Science, Isfahan University of Medical Sciences. Conflict of interest: The authors declare that there are no conflicts of interest. Authorship: M.H.R. and F.H. designed the study, searched databases, selected eligible studies, extracted data and performed statistical analyses. N.B. and J.O.T.d.Z. wrote the manuscript and helped improve English writing. Ethics of buman subject participation: Not applicable. 


\section{Supplementary material}

To view supplementary material for this article, please visit https://doi.org/10.1017/S1368980017001768

\section{References}

1. Franceschi C \& Campisi J (2014) Chronic inflammation (inflammaging) and its potential contribution to ageassociated diseases. J Gerontol A Biol Sci Med Sci 69, Suppl. 1, S4-S9.

2. Varadhan R, Yao W, Matteini A et al. (2014) Simple biologically informed inflammatory index of two serum cytokines predicts 10 year all-cause mortality in older adults. J Gerontol A Biol Sci Med Sci 69, 165-173.

3. Fraser G, Katuli S, Anousheh R et al. (2015) Vegetarian diets and cardiovascular risk factors in black members of the Adventist Health Study-2. Public Health Nutr 18, 537-545.

4. Tonstad S, Stewart K, Oda K et al. (2013) Vegetarian diets and incidence of diabetes in the Adventist Health Study-2. Nutr Metab Cardiovasc Dis 23, 292-299.

5. Kahleova H, Matoulek M, Bratova M et al. (2013) Vegetarian diet-induced increase in linoleic acid in serum phospholipids is associated with improved insulin sensitivity in subjects with type 2 diabetes. Nutr Diabetes 3, e75.

6. Wang F, Zheng J, Yang B et al. (2015) Effects of vegetarian diets on blood lipids: a systematic review and meta-analysis of randomized controlled trials. J Am Heart Assoc 4, e002408.

7. Yang SY, Li XJ, Zhang W et al. (2012) Chinese lactovegetarian diet exerts favorable effects on metabolic parameters, intima-media thickness, and cardiovascular risks in healthy men. Nutr Clin Pract 27, 392-398.

8. Huang T, Yang B, Zheng J et al. (2012) Cardiovascular disease mortality and cancer incidence in vegetarians: a meta-analysis and systematic review. Ann Nutr Metab 60, 233-240.

9. Li D (2011) Chemistry behind vegetarianism. J Agric Food Chem 59, 777-784.

10. Chen CW, Lin YL, Lin TK et al. (2008) Total cardiovascular risk profile of Taiwanese vegetarians. Eur J Clin Nutr $\mathbf{6 2}$, 138-144.

11. Fontana L, Meyer TE, Klein S et al. (2007) Long-term low-calorie low-protein vegan diet and endurance exercise are associated with low cardiometabolic risk. Rejuvenation Res 10, 225-234.

12. Krajcovicova-Kudlackova M \& Blazicek P (2005) C-reactive protein and nutrition. Bratisl Lek Listy 106, 345-347.

13. Fontana L, Shew JL, Holloszy JO et al. (2005) Low bone mass in subjects on a long-term raw vegetarian diet. Arch Intern Med 165, 684-689.

14. Szeto YT, Kwok TC \& Benzie IF (2004) Effects of a longterm vegetarian diet on biomarkers of antioxidant status and cardiovascular disease risk. Nutrition 20, 863-866.

15. Glick-Bauer M \& Yeh MC (2014) The health advantage of a vegan diet: exploring the gut microbiota connection. Nutrients 6, 4822-4838.

16. Boulange CL, Neves AL, Chilloux J et al. (2016) Impact of the gut microbiota on inflammation, obesity, and metabolic disease. Genome Med 8, 42.

17. Sutliffe JT, Wilson LD, de Heer HD et al. (2015) C-reactive protein response to a vegan lifestyle intervention. Complement Ther Med 23, 32-37.

18. Sebekova K, Boor P, Valachovicova M et al. (2006) Association of metabolic syndrome risk factors with selected markers of oxidative status and microinflammation in healthy omnivores and vegetarians. Mol Nutr Food Res 50 , 858-868.
19. Mezzano D, Munoz X, Martinez C et al. (1999) Vegetarians and cardiovascular risk factors: hemostasis, inflammatory markers and plasma homocysteine. Thromb Haemost 81, 913-917.

20. Lee YJ, Wang MY, Lin MC et al. (2016) Associations between vitamin B-12 status and oxidative stress and inflammation in diabetic vegetarians and omnivores. Nutrients $\mathbf{8}, 118$.

21. Moher D, Liberati A, Tetzlaff J et al. (2010) Preferred reporting items for systematic reviews and meta-analyses: the PRISMA statement. Int J Surg 8, 336-341.

22. Wells G, Shea B, O'Connell D et al. (2000) The NewcastleOttawa Scale (NOS) for assessing the quality of nonrandomised studies in meta-analyses. http://www.ohri.ca/programs/ clinical_epidemiology/oxford.asp (accessed July 2017).

23. Hedges LV \& Olkin I (2014) Statistical Methods for MetaAnalysis. Orlando, FL: Academic Press.

24. DerSimonian R \& Laird N (1986) Meta-analysis in clinical trials. Control Clin Trials 7, 177-188.

25. Egger M, Davey-Smith G \& Altman D (2008) Systematic Reviews in Health Care: Meta-Analysis in Context. Chichester: John Wiley \& Sons.

26. Mittlböck M \& Heinzl H (2006) A simulation study comparing properties of heterogeneity measures in metaanalyses. Stat Med 25, 4321-4333.

27. Higgins JPT \& Green S (2011) Cochrane handbook for systematic reviews of interventions. Version 5.10. The Cochrane Collaboration. http://www.cochrane-handbook. org (accessed March 2013).

28. Chen CW, Lin CT, Lin YL et al. (2011) Taiwanese female vegetarians have lower lipoprotein-associated phospholipase $A_{2}$ compared with omnivores. Yonsei Med J 52, 13-19.

29. Krajcovicova-Kudlackova M, Babinska K, Blazicek $\mathrm{P}$ et al. (2011) Selected biomarkers of age-related diseases in older subjects with different nutrition. Bratisl Lek Listy 112, 610-613.

30. Montalcini T, De Bonis D, Ferro Y et al. (2015) High vegetable fats intake is associated with high resting energy expenditure in vegetarians. Nutrients 7, 5933-5947.

31. Paalani M, Lee JW, Haddad E et al. (2011) Determinants of inflammatory markers in a bi-ethnic population. Ethn Dis 21, 142-149.

32. Sebeková K, Krajcoviova-Kudlackova M, Schinzel $\mathrm{R}$ et al. (2001) Plasma levels of advanced glycation end products in healthy, long-term vegetarians and subjects on a western mixed diet. Eur J Nutr 40, 275-281.

33. Su TC, Torng PL, Jeng JS et al. (2011) Arterial function of carotid and brachial arteries in postmenopausal vegetarians. Vasc Health Risk Manag 7, 517-523.

34. Tiahou G, Dupuy AM, Jaussent I et al. (2009) Determinants of homocysteine levels in Ivorian rural population. Int $J$ Vitam Nutr Res 79, 319-327.

35. Yang SY, Zhang HJ, Sun SY et al. (2011) Relationship of carotid intima-media thickness and duration of vegetarian diet in Chinese male vegetarians. Nutr Metab (Lond) 8, 63.

36. Yen CE, Yen CH, Cheng CH et al. (2010) Vitamin B-12 status is not associated with plasma homocysteine in parents and their preschool children: lacto-ovo, lacto, and ovo vegetarians and omnivores. J Am Coll Nutr 29, 7-13.

37. Yu X, Huang T, Weng X et al. (2014) Plasma $n-3$ and n-6 fatty acids and inflammatory markers in Chinese vegetarians. Lipids Health Dis 13, 151.

38. Chun OK, Chung SJ, Claycombe KJ et al. (2008) Serum C-reactive protein concentrations are inversely associated with dietary flavonoid intake in US adults. J Nutr 138, 753-760.

39. Masters RC, Liese AD, Haffner SM et al. (2010) Whole and refined grain intakes are related to inflammatory protein concentrations in human plasma. J Nutr 140, 587-594.

40. Vitaglione P, Mennella I, Ferracane R et al. (2015) Wholegrain wheat consumption reduces inflammation in a 
randomized controlled trial on overweight and obese subjects with unhealthy dietary and lifestyle behaviors: role of polyphenols bound to cereal dietary fiber. Am J Clin Nutr 101, 251-261.

41. Enright L \& Slavin J (2010) No effect of 14 day consumption of whole grain diet compared to refined grain diet on antioxidant measures in healthy, young subjects: a pilot study. Nutr J 9, 12.

42. Ross AB, Bruce SJ, Blondel-Lubrano A et al. (2011) A wholegrain cereal-rich diet increases plasma betaine, and tends to decrease total and LDL-cholesterol compared with a refinedgrain diet in healthy subjects. Br J Nutr 105, 1492-1502.

43. Esmaillzadeh A, Kimiagar M, Mehrabi Y et al. (2006) Fruit and vegetable intakes, C-reactive protein, and the metabolic syndrome. Am J Clin Nutr 84, 1489-1497.

44. Gao X, Bermudez OI \& Tucker KL (2004) Plasma C-reactive protein and homocysteine concentrations are related to frequent fruit and vegetable intake in Hispanic and nonHispanic white elders. J Nutr 134, 913-918.

45. Holt EM, Steffen LM, Moran A et al. (2009) Fruit and vegetable consumption and its relation to markers of inflammation and oxidative stress in adolescents. J Am Diet Assoc 109, 414-421.

46. Wannamethee SG, Lowe GD, Rumley A et al. (2006) Associations of vitamin $\mathrm{C}$ status, fruit and vegetable intakes, and markers of inflammation and hemostasis. Am J Clin Nutr 83, 567-574

47. Oliveira A, Rodriguez-Artalejo F \& Lopes C (2009) The association of fruits, vegetables, antioxidant vitamins and fibre intake with high-sensitivity C-reactive protein: sex and body mass index interactions. Eur J Clin Nutr 63, 1345-1352.

48. Brown RC, Tey SL, Gray AR et al. (2015) Association of nut consumption with cardiometabolic risk factors in the 2008/2009 New Zealand Adult Nutrition Survey. Nutrients 7, 7523-7542.

49. Mandalari G, Bisignano C, Genovese T et al. (2011) Natural almond skin reduced oxidative stress and inflammation in an experimental model of inflammatory bowel disease. Int Immunopharmacol 11, 915-924.

50. Casas-Agustench P, Bullo M \& Salas-Salvado J (2010) Nuts, inflammation and insulin resistance. Asia Pac J Clin Nutr 19, 124-130.

51. Chen CY, Holbrook M, Duess MA et al. (2015) Effect of almond consumption on vascular function in patients with coronary artery disease: a randomized, controlled, crossover trial. Nutr J 14, 61.

52. Nasca MM, Zhou JR \& Welty FK (2008) Effect of soy nuts on adhesion molecules and markers of inflammation in hypertensive and normotensive postmenopausal women. Am J Cardiol 102, 84-86.

53. Rajaram S, Connell KM \& Sabate J (2010) Effect of almondenriched high-monounsaturated fat diet on selected markers of inflammation: a randomised, controlled, crossover study. Br J Nutr 103, 907-912.

54. Moodley R, Kindness A \& Jonnalagadda SB (2007) Elemental composition and chemical characteristics of five edible nuts (almond, Brazil, pecan, macadamia and walnut) consumed in Southern Africa. J Environ Sci Health B 42, 585-591.

55. Zahradka P, Wright B, Weighell W et al. (2013) Daily nonsoy legume consumption reverses vascular impairment due to peripheral artery disease. Atherosclerosis 230, 310-314.

56. Saraf-Bank S, Esmaillzadeh A, Faghihimani E et al. (2015) Effect of non-soy legume consumption on inflammation and serum adiponectin levels among first-degree relatives of patients with diabetes: a randomized, crossover study. Nutrition 31, 459-465.
57. Gabay O, Sanchez C, Salvat C et al. (2010) Stigmasterol: a phytosterol with potential anti-osteoarthritic properties. Osteoarthritis Cartilage 18, 106-116.

58. Loizou S, Paraschos S, Mitakou S et al. (2009) Chios mastic gum extract and isolated phytosterol tirucallol exhibit antiinflammatory activity in human aortic endothelial cells. Exp Biol Med (Maywood) 234, 553-561.

59. Ovesna Z, Vachalkova A \& Horvathova K (2004) Taraxasterol and $\beta$-sitosterol: new naturally compounds with chemoprotective/chemopreventive effects. Neoplasma $\mathbf{5 1}$, 407-414

60. Ireson C, Orr S, Jones DJ et al. (2001) Characterization of metabolites of the chemopreventive agent curcumin in human and rat hepatocytes and in the rat in vivo, and evaluation of their ability to inhibit phorbol ester-induced prostaglandin $\mathrm{E}_{2}$ production. Cancer Res 61, 1058-1064.

61. Lampe JW (2003) Spicing up a vegetarian diet: chemopreventive effects of phytochemicals. Am J Clin Nutr 78, 3 Suppl., 579S-583S.

62. Stanley P \& Hegedus R (2000) Aspirin - the first hundred years. Biologist 47, 269-271.

63. Paterson JR \& Lawrence JR (2001) Salicylic acid: a link between aspirin, diet and the prevention of colorectal cancer. OJM 94, 445-448.

64. Spadafranca A, Bertoli S, Fiorillo G et al. (2007) Circulating salicylic acid is related to fruit and vegetable consumption in healthy subjects. Br J Nutr $\mathbf{9 8}, 802-806$.

65. Peltonen R, Kjeldsen-Kragh J, Haugen M et al. (1994) Changes of faecal flora in rheumatoid arthritis during fasting and one-year vegetarian diet. Br J Rheumatol 33, 638-643.

66. Wu GD, Chen J, Hoffmann C et al. (2011) Linking long-term dietary patterns with gut microbial enterotypes. Science 334, 105-108.

67. Kennedy A, Martinez K, Chuang CC et al. (2009) Saturated fatty acid-mediated inflammation and insulin resistance in adipose tissue: mechanisms of action and implications. J Nutr 139, 1-4.

68. Weaver CM \& Plawecki KL (1994) Dietary calcium: adequacy of a vegetarian diet. Am J Clin Nutr 59, 5 Suppl., 1238S-1241S.

69. Lankinen M, Schwab U, Erkkila A et al. (2009) Fatty fish intake decreases lipids related to inflammation and insulin signalling - a lipidomics approach. PLoS One 4, e 5258.

70. Zampelas A, Panagiotakos DB, Pitsavos C et al. (2005) Fish consumption among healthy adults is associated with decreased levels of inflammatory markers related to cardiovascular disease: the ATTICA study. J Am Coll Cardiol 46, 120-124.

71. Azadbakht L \& Esmaillzadeh A (2009) Red meat intake is associated with metabolic syndrome and the plasma C-reactive protein concentration in women. J Nutr 139, 335-339.

72. Ley SH, Sun Q, Willett WC et al. (2014) Associations between red meat intake and biomarkers of inflammation and glucose metabolism in women. Am J Clin Nutr 99, 352-360.

73. Sulaeman A, Keeler L, Giraud DW et al. (2001) Carotenoid content and physicochemical and sensory characteristics of carrot chips deep-fried in different oils at several temperatures. J Food Sci 66, 1257-1264.

74. Ko YC, Cheng LS, Lee CH et al. (2000) Chinese food cooking and lung cancer in women nonsmokers. Am J Epidemiol 151, 140-147.

75. Jaacks LM, Kapoor D, Singh K et al. (2016) Vegetarianism and cardiometabolic disease risk factors: differences between South Asian and US adults. Nutrition 32, 975-984. 